\title{
Malassezia Folliculitis versus Truncal Acne Vulgaris (Clinical and Histopathological Study)*
}

\author{
Khalifa E. Sharquie $^{1 \#}$, Khalil I. Al-Hamdi ${ }^{2}$, Sawsan S. Al-Haroon ${ }^{3}$, A. Al-Mohammadi ${ }^{4}$ \\ ${ }^{1}$ The Scientific Council of Dermatology and Venereology, Iraqi Board for Medical Specializations, Baghdad, Iraq; ${ }^{2}$ Department of \\ Dermatology \& Venereology, College of Medicine, University of Basrah, Basra, Iraq; ${ }^{3}$ Department of Histopathology, College of \\ Medicine, University of Basrah, Basra, Iraq; ${ }^{4}$ Department of Dermatology \& Venereology, Basrah Teaching Hospital, Basra, Iraq. \\ Email: "ksharquie@yahoo.co.uk
}

Received July $10^{\text {th }}, 2012$; revised August $12^{\text {th }}, 2012$; accepted August $23^{\text {rd }}, 2012$

\begin{abstract}
Background: Malassezia folliculitis is an infection of the hair follicle, which commonly affects young adult, and is often misdiagnosed as truncal acne. Objectives: To shed light on different clinical, histopathological, and microbiological aspects of Malassezia folliculitis and to be compared with truncal acne. Patients and Methods: This is a descriptive comparative cross sectional, out patient based study, which was conducted at the Department of Dermatology, Basrah Teaching Hospital from October 2008 to October 2009. Total number of 113 patients with papular and/or pustular follicular skin lesions on the trunk were enrolled in this study. They were divided according to the clinical features, Wood's light examination, direct microscopic examination, PAS stained skin biopsy and the response to a trial of antifungal drugs into two groups: group 1: patient with Malassezia folliculitis and group 2: patient with truncal acne vulgaris. Results: Group 1: They were 53(46.9\%) out of a total 113, 33(62.3\%) males and 20(37.7\%) females, their ages ranged from 19 - 40 years. Group 2 consisted of 60(53.1\%) patients, 25(41.6\%) males and 35(58.4\%) females, whose ages ranged from $14-29$ years. The ages were earlier in the acne group in comparison with MF group $(p<0.0001)$. The Malassezia folliculitis was more common among males than females, while in truncal acne, females predominated males. The center of the back was the predominant site among MF group affecting $(90.6 \%)$ of patients with sparing the face, in contrast to truncal acne where the periphery of the back was involved in $(91.7 \%)$ and the face in $(75 \%)(p<$ 0.0001). Wood's light examination, skin scrapping and PAS stained skin biopsies were also positive in all patients with MF in contrast to acne group where all these tests were negative. All MF patients showed marked response to a two weeks trial of antifungal while the reverse is true for the acne patients, whereas the antibiotic was the second most common leading aggravating factor in $20(37.7 \%)$ of cases with MF, which was significantly different from acne group $(\mathrm{p}<0.0001)$. Conclusion: Malassezia folliculitis should be considered in young adults with an itchy papulopustulr follicular eruptions affecting the trunk that should be differentiated from truncal acne by their characteristic clinical, histopathological features and its remarkable response to antifungal therapy.
\end{abstract}

Keywords: Malassezia Folliculitis; Basrah; Iraq

\section{Introduction}

Malassezia Folliculitis (MF): its an infection of the hair follicle that is thought to be caused by the common cutaneous lipophilic yeast like fungus, Malassezia furfur (Pityrosporum ovale) and possibly other strains of $M a-$ lassezia $[1,2]$. MF is a clinically distinct condition that is most often seen in teenagers or young adult males [3-5]. The diagnosis of MF depends on characteristic morphological picture, where the rash is dimorphic, with pruritic erythematous follicular papules and pustules. Affecting

\footnotetext{
*Disclosure: This study was an independent study and not funded by any of the drug companies.

${ }^{\#}$ Corresponding author.
}

mainly the upper back and some time adjacent areas. Wood's light examination may help in the diagnosis of MF, where the lesions of MF fluoresce a bright yellow-green color or some time bright blue or white fluorescence $[4,6]$. Direct microscopical examination by $10 \%$ $\mathrm{KOH}$ can be used to confirm the diagnosis of MF [7,8], where examination reveals abundant round spores budding yeast cells which supports the diagnosis [6,9]. Skin biopsy stained with Periodic-Acid Schiff (PAS), show clusters of yeasts within the dilated follicles surrounded by inflammatory cells [6]. MF is a controversial entity, but its prompt response to antifungal agents suggests that MF yeast are indeed pathogenic and this response to antifungal drugs whether topical or systemic will again 
support the diagnosis $[5,6,10]$. MF should be differentiated from tuncal acne as traditional acne therapies, especially antibiotics, worsen MF [11,12]. Acne vulgaris may be distinguished by the presence of comedones, cysts and scars, which are absent in MF, in addition to the presence of acne lesion elsewhere (e.g. face) and absence of itching. So these points can differentiate acne from MF $[4,13]$.

The aim of this study is to shed light on different clinical, histopathological, and microbiological aspects of MF among Iraqi patients and to detect the similarities and differences among cases of MF and that of truncal acne.

\section{Patients and Methods}

This is a descriptive comparative cross sectional, out patient based study, which was conducted at the Department of Dermatology and Venereology of Basrah Teaching Hospital from October 2008 to October 2009. A total number of 113 patients with truncal papular and/or pustular follicular skin lesions were enrolled in this study. All patients were interviewed where a full history was taken from each one with full clinical examination. Wood's light examination, skin scraping test for direct microscopical examination and biopsy of skin lesion was taken and stained with PAS stain were done for all patients. A trial of systemic and topical antifungal was given for all patients for 2 weeks (in a dose of two capsules of $150 \mathrm{mg}$ fluconazole (ABBOTT, France) weekly and Selenium sulphide 1\% lotion (CIPIA LTD, India) was applied to the affected areas daily and left overnight at bedtime to be washed off the next morning for 2 weeks, Then the response was checked after 2 weeks of treatment. The patients were considered as responder if they showed: Improvement of their clinical features, negative Wood's light examination and negative $\mathrm{KOH}$ examination. The nature of the trial was explained to the patients and the formal consent was obtained from them or their parents and approved by the ethical committee of Iraqi Board of Dermatology. They were divided according to the above clinical and laboratory features and the response to of antifungal drugs into two groups: group 1: patient with Malassezia folliculitis and group 2: patient with truncal acne vulgaris. Patients were excluded from the study when there are history of allergy or any other contraindications to antifungal drugs; those with history of using topical or systemic steroid within the last 2 months period prior to their inclusion in the study; pregnant and breast-feeding women; those patients with features of both diseases and those refusing the examination, skin scraping, biopsy and therapeutic trial.

A descriptive statistics like mean and SD (standard deviation) together with analytic statistics like chi squared test, t-test or Fischer exact test have been done when appropriate.

\section{Results}

Group 1 (MF): included 53/113(46.9\%) patients, $33(62.3 \%)$ of them were males and $20(37.7 \%)$ were females, their ages ranged from 19 to 40 years with a mean age \pm SD of $28.88 \pm 5.3$ years. Group 2 (Truncal acne): included $60 / 113(53.1 \%)$ patients, $25(41.6 \%)$ of them were males and $35(58.4 \%)$ were females, their ages ranged from 14 to 29 years with a mean age \pm SD of $20.73 \pm 3.4$ years. The age of onset of the MF group ranged from 18 to 39 years with a mean \pm SD of $27.8 \pm$ 5.2 years, whereas the age of onset in truncal acne group ranged from 11 to 27 years with a mean \pm SD of $15.85 \pm$ 3.7 years. A statistical significant difference was found between MF and truncal acne groups regarding their ages and age of onset ( $p$-value $<0.0001$ ), where truncal acne occurred at younger age and earlier than MF. There was a male predominance among MF (male:female $=1.65: 1$ ) while in truncal acne group females predominated males (female:male $=1.4: 1$ ), with a significant difference between both groups in regard to the sex ( $p$-value $=0.029$ ) The center of the back was the predominant site involved in $48(90.6 \%)$ cases of MF group, while the periphery of the back was involved in 55(91.7\%) cases of truncal acne group, this was a statistically significant difference (p-value $<0.0001)$ (Table 1). In addition, face was involved in 45 cases $(75 \%)$ of truncal acne group, which was spared in all patients of MF group ( $p$-value $<0.0001$ ). The leading aggravating factors that were noticed by patients in both groups were shown in the (Table 2). The

Table 1. Predominant sites of lesions on the trunk among both groups.

\begin{tabular}{|c|c|c|c|}
\hline \multirow{2}{*}{ Site of lesion on the trunk } & \multicolumn{2}{|c|}{ Groups } & \multirow{2}{*}{ Total } \\
\hline & MF & Acne & \\
\hline Center of the back & $48(90.6 \%)$ & - & $48(42.5 \%)$ \\
\hline Periphery of the back & - & $55(91.7 \%)$ & $55(48.7 \%)$ \\
\hline Both periphery and center of back & $5(9.4 \%)$ & $5(8.3 \%)$ & $10(8.8 \%)$ \\
\hline Total & $53(100 \%)$ & $60(100 \%)$ & $113(100 \%)$ \\
\hline
\end{tabular}

p-value $<0.0001$.

Table 2. The type of the aggravating factors among both groups.

\begin{tabular}{|c|c|c|c|}
\hline \multirow{2}{*}{ Type of aggravating factors } & \multicolumn{2}{|c|}{ Groups } & \multirow{2}{*}{ Total } \\
\hline & MF & acne & \\
\hline None & $5(9.4 \%)$ & $7(11.7 \%)$ & $12(10.6 \%)$ \\
\hline Hot weather \& sweating & $28(52.8 \%)$ & $30(50.0 \%)$ & $58(51.3 \%)$ \\
\hline Antibiotics & $20(37.7 \%)$ & - & $20(17.7 \%)$ \\
\hline Stress & - & $9(15 \%)$ & $9(8 \%)$ \\
\hline Diet & - & $8(13.3 \%)$ & $8(7.1 \%)$ \\
\hline Premenstrual flare (female only) & - & $6(10 \%)$ & $6(5.3 \%)$ \\
\hline Total & $53(100 \%)$ & $60(100 \%)$ & $113(100 \%)$ \\
\hline
\end{tabular}


hot weather and sweating were the commonest leading aggravating factors among both groups with no significant difference $(p$-value $=0.456)$. While antibiotic was the second most common leading aggravating factor in $20(37.7 \%)$ of cases with MF, which was significantly different from truncal acne group (p-value $<0.0001)$ (Table 2). Hirsutisim and melasma were reported in 9 $(15 \%)$ females patients of truncal acne group which was significantly different from those of MF group ( $\mathrm{p}$-value = 0.003 ). Wood's light examination was positive in all cases of MF in contrast to truncal acne group where it was negative in all cases. On the other hand, scraped material was positive for yeast type of fungus in all cases of MF but it was negative for all patients of truncal acne group.

The skin biopsies that were taken from all patients with MF and stained with PAS stain showed buds of yeast filling the dilated hair follicles surrounded by inflammatory cell infiltrate (Figure 1), in contrast to skin biopsies of patients with truncal acne where no one showed these characteristic findings (Figure 2). All patients of MF showed a remarkable prompt response to the two weeks treatment by systemic and topical antifungal drugs (Figure 3), while no patient with truncal acne showed any response to the treatment (Figure 4).
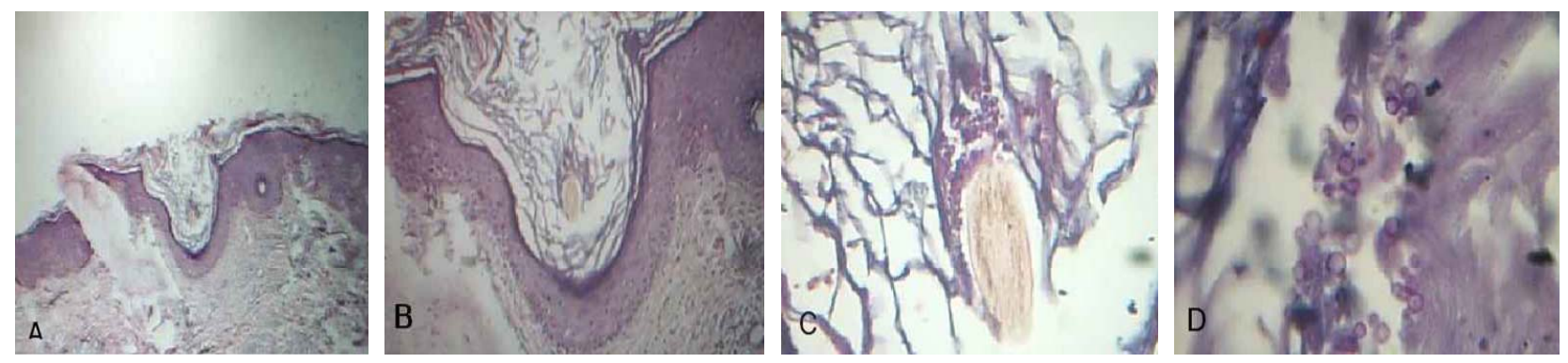

Figure 1. Malassezia folliculitis (PAS stained skin biopsy): A. Sowing follicular dilatation filled with keratinous materials $(\times 100)$; B. Same slide showing follicular dilatation filled with keratinous materials and Perifollicular inflammatory cell infiltrate $(\times 250)$; C. Same slide showing the buds of Yeast $(\times 400)$; D. Same slide showing the buds of Yeast $(\times 1000)$.
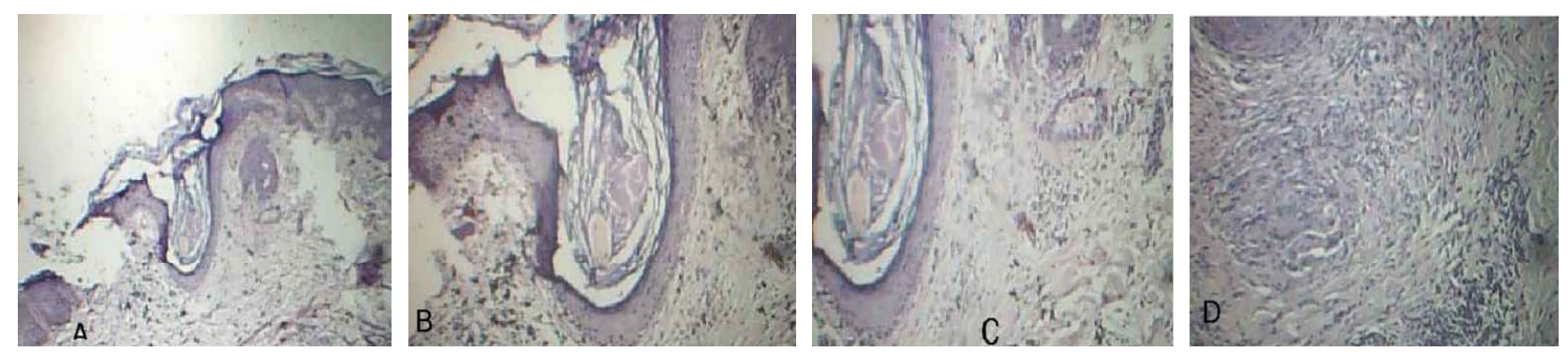

Figure 2. truncal acne (PAS stained skin biopsy): A. Showing follicular dilatation filled with keratinous materials $(\times 100)$; B. Same slide also showing follicular dilatation filled with keratinous materials and there is no any bud of Yeast $(\times 250)$; C. Same slide showing Perifollicular inflammatory cell infiltrate and there is no any buds of Yeast $(\times 400)$; D. Same slide showing Perifollicular inflammatory cell infiltrate $(\times 1000)$.
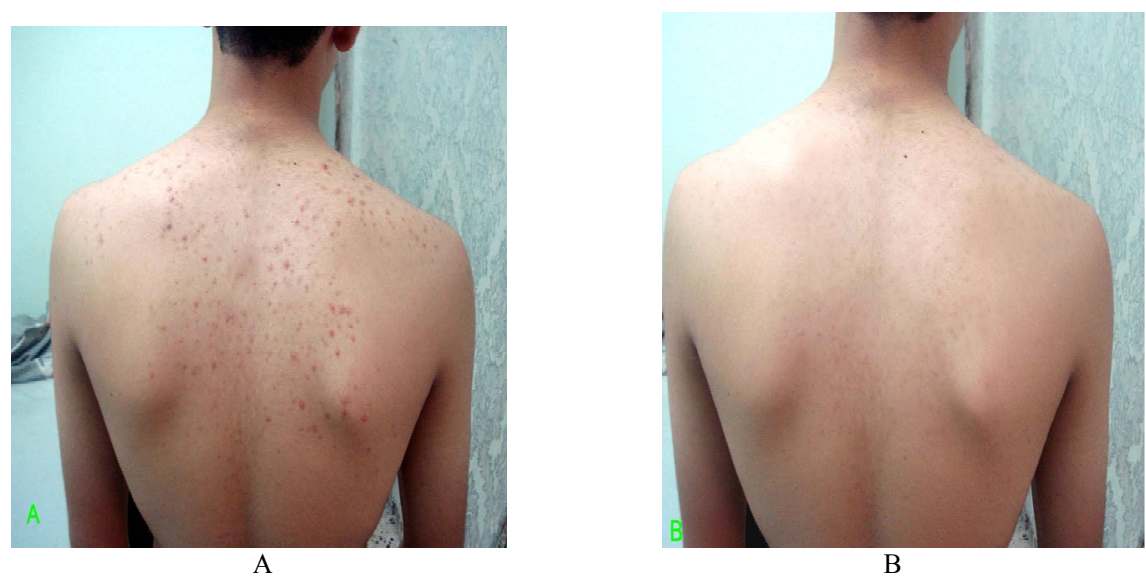

Figure 3. Patient with Malassezia folliculitis: A. Before treatment with antifungal; B. After treatment with antifungal. 


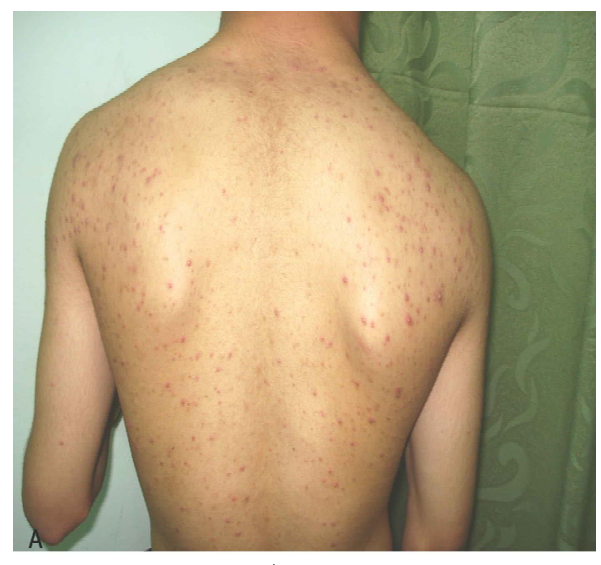

A

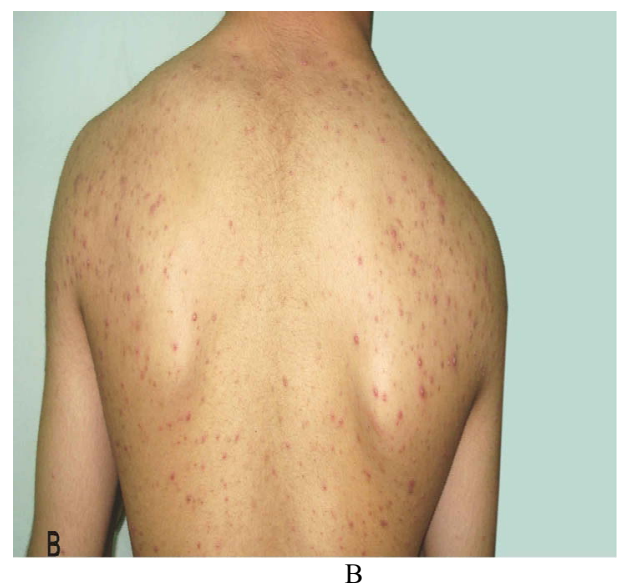

B

Figure 4. Patient with truncal acne: A. Before treatment with antifungal; B. After treatment with antifungal.

\section{Discussion}

MF is a commonly misdiagnosed inflammatory skin disorder that was first described in 1969 by Weary et al., presented with itchy papulopustular follicular skin lesions affecting the trunk of young adult people, caused by Malassezia furfur which is lipophilic yeast like fungus [3-5].

This study showed that MF affecting young adult with a mean age of $28.88 \pm 5.3$ years and this is similar to many other published studies [3,11,12], while truncal acne affecting younger age group with a mean age of $20.73 \pm 3.4$ years $(\mathrm{p}<0.0001)$ and this is comparable to previous Iraqi study on acne [14,15].

The age of onset of patients with MF ranged from 18 39 years with a mean of $27.8 \pm 5.2$ years, which is comparable to that of previous published studies $[10-12,16]$. On the other hand, the early age of onset in truncal acne group ranged from $11-27$ years with a mean of $15.85 \pm$ 3.7 years $(\mathrm{p}<0.0001)$, which is similar to that reported by previous Iraqi study in which the age of onset of acne ranged from 11 - 29 years with a mean of 16.5 year $[14,15]$. This may be attributed to the fact that acne represent the first event of hormonal changes that leads to maturation of sebaceous glands with subsequent well recognized changes while MF tends to occur when the sebaceous glands are fully matured creating a favorable media like seborrhea for the proliferation of Malassezia species [1,4,17-20].

On the other hand, the center of the back was found to be the predominant site affected in $90.6 \%$ of the patients with MF while the periphery of the back was involved in 91.7\% patients with truncal acne. These observations have not been mentioned before and may be attributed to the pityrosprum yeast that is normally inhabiting the center of the back in higher percent in comparison with periphery as mentioned by previous Iraqi study [17]. In addition, it was reported that more than $90 \%$ of healthy people have higher percent of pityrosporum yeast on the inter scapular area of the back $[2,8,11,13,21-23]$. In addition to the back, the face was also involved in $(75 \%)$ of patients with truncal acne, in contrast to MF where no patient in present study had facial lesions (p-value < 0.0001 ) and this result was comparable to that reported by previous published studies $[8,11,24,25]$, although some studies found that the periphery of the face was also involved in MF [3,12]. Sparing of the face in MF is probably attributed to regional variation regarding the number of Malassezia yeast or because the face is frequently washed daily so reducing the sebum at the surface of facial skin, thus decreasing the favorable media required for the proliferation of the organism $[10,11,14$, $18,22]$. It has been found also that hot weather and sweating were the commonest aggravating factors in both groups $(p=0.456)$, although heat does not increase the production of sebum but it may increase the flow of sebum to the skin surface, so exacerbating both diseases. This observation was mentioned by K.B. Lim from Singapore and Philippine for patients with MF [10,23,25]. This was also observed among patients with acne in other Iraqi studies $[14,15]$ and this fact was also proved by other Korean published study on both groups [11].

Moreover, this study showed the antibiotic was the second most common leading aggravating factor in 20 $(37.7 \%)$ of cases with MF. This observation was also reported by many other studies and this could explained by the fact that antibiotics destroy and alter the normal bacterial flora, so enhancing the proliferation of malassezia yeast resulting in the clinical features of MF. So MF that was misdiagnosed and treated by conventional acne medications (antibiotics) may be exacerbated by such therapy $[4,10-12,26]$.

In regard to other parameters for the diagnosis of MF; the Wood's light examination was positive in all patients with MF, in contrast to patients with truncal acne where this test was negative in all cases. Positive Wood's light 
in MF is probably attributed to a specific compounds that are synthesized by malassezia called pityriacitrin and Pityrialactone that absorbs light and fluoresces under 365 $\mathrm{nm}$ ultraviolet light $[4,27,28]$. This finding was also observed by many other published studies supporting the idea that MF is caused by malassezia yeast $[3,4,6,23]$.

Regarding other diagnostic criteria, it has been found that skin scraping test was positive in all cases of MF in contrast to acne patients in whom the test was negative. Although Malassezia yeast is a normal skin flora inhabiting the upper and middle follicular ostium, but to be detected by direct microscopically examination, through $10 \% \mathrm{KOH}$ preparation, it should be present in large number which is the case in MF. While in acne lesions the organism is altered and destroyed by the proliferation of other bacterial flora, so they are less in number and difficult to be detected by ordinary scrapping and need to be cultured in a special media. Moreover PAS stained skin biopsy showed the characteristic features of MF in all patients but no one of truncal acne group showed the same changes. Accordingly the clinical features, the Wood's light examination, the skin scrapping and skin biopsy are an important diagnostic criteria of MF that should be considered in the diagnosis of MF and to differentiate it from truncal acne. These criteria were also reported by other studies [3,4,6,10-12,16,23,29]. In the present work, all patients with MF responded promptly to the two weeks trial of systemic and topical antifungal drugs, in contrast to patients with truncal acne who did not show any response to this regimen. The prompt response to treatment support the idea considering Malassezia yeast as a cause of MF; meanwhile it confirmed it's diagnosis and help to differentiate it from truncal acne. These findings are compatible with other reported studies [6,10-12,24,29].

In addition, it has been found that the hirsutisim and melasma occurred only among patients with truncal acne group that is significantly differed from MF group ( $\mathrm{p}$-value $=0.003$ ).This finding is probably attributed to the fact that acne, hirsutisim and melasma are androgen related diseases: this was also reported by previous Iraqi study on acne $[14,15]$.

In conclusion, MF should be considered in young adults with an itchy papulopustular follicular eruptions affecting the trunk, which should be differentiated from truncal acne by their characteristic clinical, histopathological features and its remarkable response to antifungal therapy.

\section{REFERENCES}

[1] J. Faergemann, S. Johansson, O. Bäck and A. Scheynius, "An Immunologicand Cultural Study of Pityrosporum Folliculitis," Journal of the American Academy of Dermatology, Vol. 14, No. 3, 1986, pp. 429-433.
[2] S. O. Roberts, "Pityrosporum Orbiculare: Incidence and Distribution on Clinically Normal Skin," British Journal of Dermatology, Vol. 81, No. 4, 1969, pp. 264-269. doi:10.1111/j.1365-2133.1969.tb13978.x

[3] O. Back, J. Faergemann and R. Hornquist, "Pityrosporum Folliculitis: A Common Disease of the Young and Middle Aged Persons," Journal of the American Academy of Dermatology, Vol. 12, No. 1, 1985, pp. 56-61.

[4] M. Siobahn, "Pityrosporum Folliculitis in e-Medicine Dermatology," 2008. http://www.eMedicine.com

[5] R. J. Hay and M. K. Moore, "Mycology," In: T. Burns, N. Cox, C. Griffiths and S. R. Breathnach, Eds., Rook's Text Book of Dermatology, 7th Edition, London Blackwell Publishing Company, Oxford, England, 2004, pp. 31.131.15 .

[6] D. J. William, "Timothy GB and Dirk ME. Diseases Resulting from Fungi and Yeast," In: Andrews Diseases of the Skin, Clinical Dermatology, 10th Edition, W. B. Sounder Company, Philadelphia.

[7] H. Molly and B. Jack, "Fungal Diseases," In: E. Longley, E. David, J. Rosalie, L. Bernett and F. Murphy and George, Atlas and Synopsis of Lever's Histopathology of the Skin, 9th Edition, Lippincott Williams, Wilkins, London, 2005.

[8] W. C. Sloof, "Pityrosporum Sabouraud. Taxonomic Study," Medical Mycology, Vol. 39, No. S1, 2000, p. 9.

[9] P. J. Mathew and P. H. Michael, "Yeast Infection of Skin," In: M. F. Irwin, Ed., "FitzPatrick's Dermatology in General Medicine," 7th Edition, Philadelphia, 2008, pp. 1828-1830.

[10] K. B. Lim and T. Tan, "The Epidemiology of Pityrosporum Folliculitis in Singapore," Pediatric Dermatology, Vol. 26, 1999, p. 7.

[11] H. J. Yu, S. K. Lee, S. J. Son, Y. S. Kim, H. Y. Yang and J. H. Kim, "Steroid Acne vs Pityrosporum Folliculitis: The Incidence of Pityrosporum ovale and the Effect of Antifungal Drugs in Steroid Acne," International Journal of Dermatology, Vol. 37, No. 10, 1998, pp. 772-777. doi:10.1046/j.1365-4362.1998.00229.x

[12] M. Abdel-Razek, G. Fadaly, M. Abdel-Raheim and F. AlMorsy, "Pityrosporum (Malassezia) Folliculitis in Saudi Arabia: Diagnosis and Therapeutic Trials," Clinical and Experimental Dermatology, Vol. 20, No. 5, 1995, pp. 406-409. doi:10.1111/j.1365-2230.1995.tb01358.x

[13] J. Faergemann, "Pityrosporum Ovale and Skin Diseases," The Keio Journal of Medicine, Vol. 42, No. 3, 1993, pp. 91-94.

[14] E. K. Sharquie, A. Gumar, Z. Al-Kodsi, "Acne Vulgaris: Epidemiology and Grading," Saudi Medical Journal, Vol. 12, 1991, pp. 44-47.

[15] E. K. Sharqui, K. I. Al-Hamdi, A. A. Al-Nuaimy and R. A. Al-battat, "Scaring and Non-Scaring Facial Acne Vulgaris and the Frequency of Associated Skin Diseases," Iraqi Postgraduate Medical Journal, Vol. 8, No. 4, 2009, pp. 332-338.

[16] A. Katherine, M. Susan and K. W. Sweeney, "Pityrosporum Folliculitis Diagnosis and Management in $6 \mathrm{Fe}$ male Adolescents with Acne Vulgaris," Archives of Pedi- 
atrics \& Adolescent Medicine, Vol. 159, No. 1, 2005, pp. 64-67. doi:10.1001/archpedi.159.1.64

[17] K. E. Sharquie, M. G. Al-Rubyae and J. R. Al-Rawi, "Prevalence of Pityrosporum Orbiculare on Normal Skin of Iraqi Healthy People," Eastern Mediterranean Health Journal, Vol. 11, No. 3, 2005, pp. 511-514.

[18] P. J. Sunenshine, "Tinea Versicolor," International Journal of Dermatology, Vol. 37, No. 9, 1998, pp. 648-655. doi:10.1046/j.1365-4362.1998.00441.x

[19] W. D. James, T. G. Berger and D. M. Elston, “Acne," In: Andrews Disease of the Skin, Clinical Dermatology, 10th Edition, W. B. Sounder Company, Philadelphia, 2006, pp. 231-242.

[20] J. A. A. Hunter, J. A. Savin and M. V. Dahl, "Sebaceous and Sweat Gland Disorder," In: Clinical Dermatology, 4th Edition, Blackwell Publishing Company, Oxford, 2008, pp. 162-169.

[21] A. A. Hartmann, "The Influence of Various Factors on the Human Resident Skin Flora," Seminars in Dermatology, Vol. 9, No. 4, 1990, pp. 305-308.

[22] J. Faergemann, I. M. Bergbrant, M. Dohse, A. Scott and G. Westgate, "Seborrhoeic Dermatitis and Pityrosporum Folliculitis: Characterization of Inflammatory Cells and Mediators in the Skin by Immunohistochemistry," British Journal of Dermatology, Vol. 144, No. 3, 2001, pp. 549556. doi:10.1046/j.1365-2133.2001.04082.x

[23] J. Faergemann, "Pityrosporum-What's New?" Mycoses, Vol. 40, No. S1, 1997, pp. 29-32.
[24] A. Lévy, de C. M. Feuilhade, L. Dubertret and P. Morel, "Malassezia Folliculitis: Characteristics and Therapeutic Response in 26 Patients," Annales de Dermatologie et de Vénéréologie, Vol. 134, No. 11, 2007, pp. 823-828. doi:10.1016/S0151-9638(07)92824-0

[25] S. Jacinto-Jamora, J. Tamesis and M. L. Katigbak, "Pityrosporum Folliculitis in the Philippines: Diagnosis, Prevalence, and Management," Journal of the American Academy of Dermatology, Vol. 24, No. 5, 1991, pp. 693-696.

[26] A. K. Gupta, R. Batra, R. Bluhm and T. Boekhout, "Skin Disease Associated with Malassezia Species," Journal of the American Academy of Dermatology, Vol. 51, No. 5, 2004, pp. 785-798.

[27] P. Mayser, M. Schutz, H. C. Schuppe and A. S. Jung, "Pityriacitrin-An Ultraviolet Indole Alkaloid from the Yeast Malassezia furfur," Archives of Dermatology Research, Vol. 294, No. 3, 2002, pp. 131-134. doi:10.1007/s00403-002-0294-2

[28] P. Mayser, M. Schutz, H. C. Schuppe and A. S. Jung, "Pityrialactone-A New Fluorochrome from the Tryptophan Metabolism of Malassezia furfur," Antonie van Leeuwenhoek, Vol. 84, No. 3, 2003, pp. 185-191. doi:10.1023/A:1026042903354

[29] G. P. Ford, F. A. Ive and G. Midgley, "Pityrosporum Folliculitis and Ketoconazole," British Journal of Dermatology, Vol. 109, No. 6, 1982, pp. 691-695. doi:10.1111/j.1365-2133.1982.tb00530.x 